\title{
Web-Conference Lecturing: In Dialogue with Student Experiences During a Pandemic
}

\author{
Visual Technologies as a Panacea for Social Isolation
}

\author{
Fiona Westbrook | ORCID: 0000-0002-0744-6721 \\ M.D., Bundoora East Campus, RMIT University, Melbourne, Australia \\ fiona.westbrooko@gmail.com
}
Anna Tibb | ORCID: 0000-0001-5532-9952
MA, RMIT University, Melbourne
allytibb@gmail.com

\author{
Leigh Blackall \\ PhD, RMiт University, Melbourne, Australia \\ leigh.blackall@rmit.edu.au
}

in collaboration with

Hepsibah Zabde | ORCID: 0000-0003-2142-3670

MA, RMIT University, Melbourne, Australia

hepsibah.zabde@rmit.edu.au

\begin{abstract}
COVID-19 is an omnipresent feature of 2020, both globally and within Australia. For university students, a consequence of this has been the shift from on-campus to online delivery. Exploring these visual realities for lecturers and students, this article engages in Bakhtinian dialogism; a dialogic interaction that is born between peoples searching for meaning (Bakhtin, 1986). To do so, the authors engaged with and responded to students' survey data whom they lecture and coordinate. Although the survey had limited responses, it enabled the authors to dialogue about received knowledge (istina) from students and contemplate this in relation to the authors' own perspectives and experiences (pravda). Through this engagement, they suggest the importance of visually imbued emotive connectivity and dialogic relational care within web-conferencing, as well as didactic lecturing as valid forms of visual engagement.
\end{abstract}




\section{Keywords}

visual technologies against social isolation - pandemic - online learning web-conferencing - university students - didactic teaching - dialogic learning

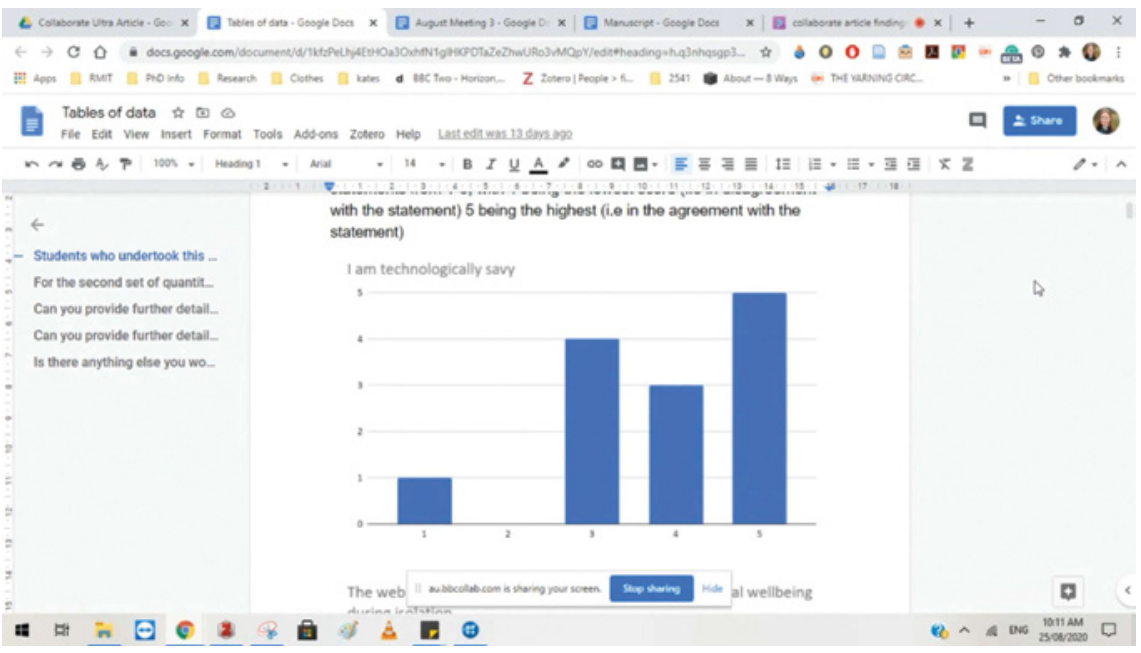

FEATURE This article comprises a video, which can be viewed here.

- This article is part of the special topic 'Visual Technologies as a Panacea for Social Isolation', edited by Rene Novak.

\section{Introduction}

Although previous research has explored the cultural dimensions, challenges and strengths of online learning (Chen et al., 2008; Erichsen \& Bolliger, 2011; Zhao \& McDougall, 2008), the CoviD-19 pandemic offers new terrain for consideration. Learning environments primarily used to facilitate on-campus learning changed to fully online almost overnight (Rapanta et al., 2020). This sudden and total reliance brings distant issues closer, including how visual technologies may be aiding or hindering students. Concern already exists for how the implicit premises of visual technology's design and implementation does or does not align with the needs and expectations of an institution of learning, and its researchers, lecturers and students (Awbrey, 2002). Whilst the coordinates of these platforms can be shown to harbour a deterministic hegemony 
of capitalist and technocratic ideology (Postman 1992), the pandemic response expects lecturers and coordinators to suspend these concerns and quickly find ways to establish visual forms of connectivity and community (Rapanta et al., 2020). Accordingly, lecturers have new challenges, but also visual possibilities in responding and communicating with students through web-conferencing. We assert that students are additionally emphasised in these needs, requiring a reconceptualising of the lecturer's role and web-conferencing's visually mediated space. Seeking to better understand the challenges and possibilities afforded to students during the pandemic, we engage with and respond to students' survey data whom we lecture and coordinate. Bringing Bakhtinian dialogism to bear on this data enabled us to dialogue about received knowledge (istina) from the students and contemplate this in relation to our own perspectives and experiences (pravda). Within this, dialogic relational care and didactic visual teaching emerged as emotive challenges and possibilities for connection.

\section{Engaging with the Literature}

In web-conferencing's physically distanced but visually emphasised online space, students' needs are both intensified and necessitated by the pandemic with concerns for the lack of connectivity and visual stimulus available within social isolation (Rapanta et al., 2020). To mitigate these concerns, many courses which were forced online due to the pandemic have added visual technologies such as web-conferencing (Jandrić et al., 2020; Rapanta et al., 2020). Highlighting visual technologies' limitations, Roland Barthes (1980) expressed "what is terrible about a photograph is that there is no depth in it, that it is clear evidence of what was there" (p. 352, as cited in Jay, 1993, p. 266). Similarly, webconferencing's visual affordances over a distance may not provide the depth of connectivity that students need during a pandemic. Reflecting on moving video, Christian Metz (1984) contends that whilst the stillness of photographs maintains the "dead as being dead" (p.84, as cited in Jay, 1993, p. 271), moving images give a fragile semblance of life. In the context of web-conferencing during the pandemic, this visual technology may bring to life the social and connectivity needs of students through video, a semblance that cannot be elicited with still images that may maintain the memory of isolation. Webconferencing's video affordances could, therefore, be a vital visual community link for students' social interactions and academic engagement.

Web-conferencing's visual technology is claimed to afford and challenge both university students and lecturers. Web-conferencing often facilitates 
visual media, including live video streaming, with a recording feature, the interactive whiteboard alongside the lecturer's video, an accompanying text chat with Emojis, live polling and quizzes, smaller group breakout rooms, as well as screen and file sharing (Chen et al., 2020). For lecturers, these visual features can afford collaborative and engaging online teaching (Chatterton, 2010). However, many authors have highlighted the unique, technical competencies required to do so, and urged for lecturer training to enable online facilitators adaption (Cornelius, 2013; Grant \& Cheon, 2007; Reushle \& Loch, 2008). Due to the pandemic, training was rushed, minimised or absent. For students, webconferencing can reduce feelings of isolation through the visual connection of virtual peers and lecturers, facilitating spontaneous dialogue (Akarasriworn \& Ku, 2013; Chen et al., 2020; Yamagata-Lynch, 2014). However, the degree to which this extends to the pandemic's social isolation is unknown. Student challenges with web-conferencing also relate to this technology's visual performance, such as poor quality of video and a weak internet connection, inhibiting their engagement (Akarasriworn \& $\mathrm{Ku}$, 2013; Cornelius, 2014).

International students from Southeast Asia, including a majority of Chinese, Indian and Vietnamese citizens, comprise a large percent of Australian university students (Australian Trade and Investment Commission, 2020), and reflected the majority of our student survey demographic. Online international student literature has centred on the challenges situated within this digital visuality. One of these challenges is the traditional view of lecturer, seen as an irreproachable knowledgeable other (Chen et al., 2008; Erichsen \& Bolliger, 2011; Zhao \& McDougall, 2008). This can equate to international students' expectations for high dependency, visual approaches which is at tension with Constructivist-based online learning, potentially resulting in heightened isolation (Chen et al., 2008; Erichsen \& Bolliger, 2011). Further online challenges include international students' perception of minimal lecturer input and opportunities to develop lecturer-student relationships (Chen et al., 2008). This is an issue increased by the casualisation of lecturers (Hellsten \& Prescott, 2004).

Another significant challenge for international students is the desire for, and perceived lack of, cultural experiences in visually digital worlds that lack a local 'look' (Erichsen \& Bolliger, 2011). Discussing visual reproductions, John Bergers (1972) highlighted that before the camera, paintings were once woven into locations such as churches, appearing to tell the story of the building. Transported by technological advancements, the visual is no longer tied to the boundaries of time or space but rather seen in the context of the seer's own life (Bergers, 1972). In this way, international students' experiences of the online is within the familiarity of their own homes. Jonathan Crary (1992) describes 
reproductions as being "nullified cultural experiences" (p.1). Consequently, international students may thus be receiving these nullified online experiences due to the "ubiquitous implantations of fabricated visual 'spaces"' (Crary, 1992, p. 1) that may not afford connectivity during the pandemic.

There are also strengths highlighted for international students' online experiences (although less frequently mentioned). These include Southeast Asian students' competency with computing and Internet use (Hughes, 2013), and fewer language barriers, with the time afforded in asynchronous online learning to formulate responses in English as a second language (Zhao \& McDougall, 2008). Hannon and D'Netto (2007) contend that these gains are minor in comparison to the historical developments of online technology that negatively interacts with international students' cultural and academic visual learning needs.

As early as 1999, online students have described 'distanced' learning as inhibiting their connectedness to lecturers, peers and content (Stark \& Warne, 1999). Emphasising these limitations during the pandemic, Jandrić et al., (2020) described online teaching spaces as a "devaluing of human contact" (p. 5). However, as of yet little pandemic literature has considered how visual technologies may be aiding students to overcome social isolation. The concern regarding the online may be, in part, due to the coordinates of these learning platforms. They have been perceived to display an increasingly deterministic, hegemonic neoliberal, and technocratic ideology (Blackall, 2000; Postman 1992). Online learning spaces are thus determined by the same power and influence of finance and capital that now determines Australian universities generally observed under a unifying ideology of economic rationalism (Awbrey, 2002). Bernard Stiegler (1998) contends that this industrial and market culture co-creates knowledge, displacing the human, and perhaps students' needs. Human evolution, Stiegler (1998) asserts, is determined by technology over biology. In this way, web-conferencing and students' online participation is an intertwined "co-possibility" (Stiegler, 1998, p. 141). Relating this to Derrida's concept of pharmakon, Stiegler (1998) views technology as both a cure and poison. For example, the procedural look of visual technologies and ideological language of affirmative action may be poisonous to some learners' cultural identities and needs (Hannon \& D'Netto, 2007). Coupled with the pandemics' potential mental health impacts to students (Pragholapati, 2020), web-conferencing's visual technology may cure students' pastoral care and connectedness needs. Contemplating these poisonous challenges but also the cure of webconferencing's visual possibilities, we respond to student truths with own experiences during the pandemic. 
Bringing Bakhtinian dialogism to bear on this article, the authors dialogued about the received data (istina) in relation to our visual teaching and coordinating experiences (pravda) to generate meaning (Bakhtin, 1986, 1993). Bakhtin adapted the two Russian words for truths to express knowledge and truth that is experienced (pravda) and knowledge and truth that is received (istina). For Bakhtin, meaning is generated when one co-experiences the others' subjectivity before returning to their own interpretations (Gurevitch, 200o). Embodying this process, we dialogued about the data (istina) of web-conferencing whilst reflecting on our visual teaching and coordinating experiences (pravda). Similar research by Rapananta et al., (2020) called on Bakhtin, dialogically investigating research data to ascertain meaning. They found this timely for findings on the pandemic and a means to enhance new discussion possibilities. Jandrić et al., (2019) also invoked this research design, unearthing new ways of viewing post-digital via collective dialogue; Bakhtinian dialogism has also shared academics' pandemic experiences (Jandrić et al., 2020).

Our data (istina) comprises university students who enrolled in on-campus classes, but due to the pandemic were moved to online learning. Students who answered the survey were undertaking a one-year early childhood diploma. The students were the first to experience a new program that excluded PowerPoints in order to embrace a dialogic, relational lecturer pedagogy that was collaborative and playful. The students comprised diverse demographics, with numerous first languages, age groups and nationalities, reflected in our ninety two percent of international student respondents. This cohort's pandemic-related move to online learning relied on the visual software Blackboard Collaborate Ultra, hereafter referred to as web-conferencing. Due to social-distancing measures, our dialogic analysis also occurred within this web-conferencing platform. Seizing on this visual opportunity, we present a segment of our recorded meeting composed using a screensharing feature (see here). Incorporating this video, we seek to add to innovate technological dialogues, furthering pedagogical reflections and visual possibilities. We assert thistechnologically aided and situated dialogue is increasingly important as digital technologies inherently influence and afford new dialogues (Jandrić et al., 2019), as well as perpetuating existing ones (Bowers 2000).

\subsection{Limitations}

The findings of this research are limited to the one institution and one programme of students. Out of these students, only 13 responses were received, accounting for less than ten percent of those enrolled. Although it is ultimately 
unclear why such a low percentage of students did participate in the survey, we pondered this lack of response as an answer in itself. Informed by Bakhtin (1986), we acknowledge silence as response, one where the self is not tempted into giving a "performed act" (Bakhtin, 1993, p. 21), such as a survey. Within our context, it may indicate students did not resonate with the webconferencing survey. This may be due to their familiarity and expectations of web-conferencing's visual and dialogic affordances. One student highlighted this, commenting “to be honest, I don't feel like [Blackboard] Collaborate Ultra is revolutionary, it does the job like you would expect from an application like that." The following findings may be from those who felt strongly enough toward this form of visual technology. Due in part to this and the small sample size, the data and following analysis are not indicative of generalisability. Our intention with this article is not a comfortable truth that can be curled up with (Bakhtin, 1986). Rather, we explored these responses as the Other's received knowledge (istina) in dialogue with our experiences (pravda).

\section{$4 \quad$ Visually Situated Dialogues}

Meaning emerged in the following discussion in relation to student, lecturer and coordinator experiences of the pandemic as visual, technological possibilities and challenges. The following istina and pravda emphasised that (online) learning is not an achievable product but rather a series of open points to dialogically connect (White, 2016). These open points challenged us to think more holistically about visually situated dialogic engagement within web-conferencing.

\subsection{Dialoguing within Web-conferencing's Visuality}

As lecturers, we expressed web-conferencing anxieties: a common pandemic trepidation (Mardiana, 2020). Our experiences (pravda) of web-conferencing implicated heightened performance as we attempted to facilitate dialogue, removing PowerPoints within a blank, unresponsive void. We perceived the look and feel of this void to be exaggerated due to the frequent absence of audio and camera image. This is a common phenomenon for students' in web-conferencing (Chen et al., 2020). In addition to the limited screens observable in the frame (see Figure 1), there were apprehensions of low attendance due to recording sessions which compounded monologue concerns (Jandrić et al., 2020). Early in the pandemic, we consequently did not see webconferencing's visuality as a cure to students' isolation but rather poisoning engagement. 

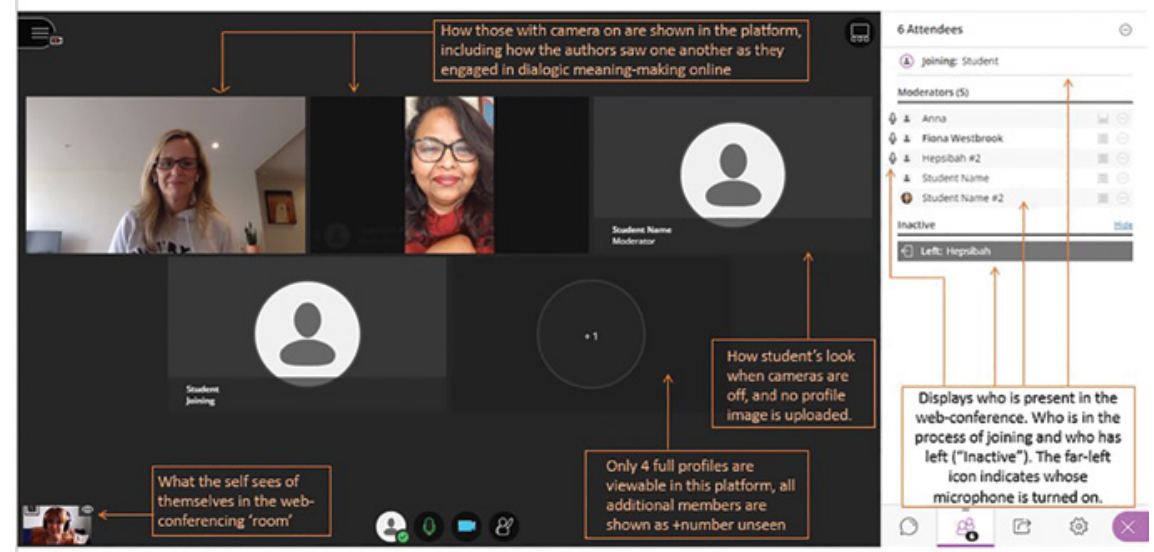

FIGURE 1 The Web-Conferencing Space

The web-conferencing sessions we feared as poisonously monologic conversely appeared to support mental wellbeing, and were considered academically helpful to some students ${ }^{1}$ (see Figure $2 \mathrm{a}-\mathrm{b}$ ). This was also reflected in qualitative feedback that emphasised connectivity:

Response 1: “... feeling disconnected and isolated it was nice to have class and see our lecturer and classmates. And it just gave that bit of motivation needed that might be the power of connection with others and the social aspect that we as humans need." (emphasis added)

Response 2: “... as days would go on in isolation, it would be wonderful to have a session. I would feel a little more connected again." (emphasis added)

Response 3: "It gives a way to connect ... and save from other mental problems like depressions in this pandemic." (emphasis added)

This data (istina) may reflect the importance of digital technologies that inherently afford visual connectivity for students during the pandemic. By seeing others, it appears this visual technology aided them in overcoming social isolation to some degree, which enabled, as Metz (1984) contends, a semblance of life through moving image. Although our lived experience (pravda) reflected student lurkers, a position of observing and minimal interaction, this may not

1 Online learning was not favoured by all respondents. Three out of thirteen students saw it as an inferior form of engagement. 


\section{Web conferencing has helped me academically}

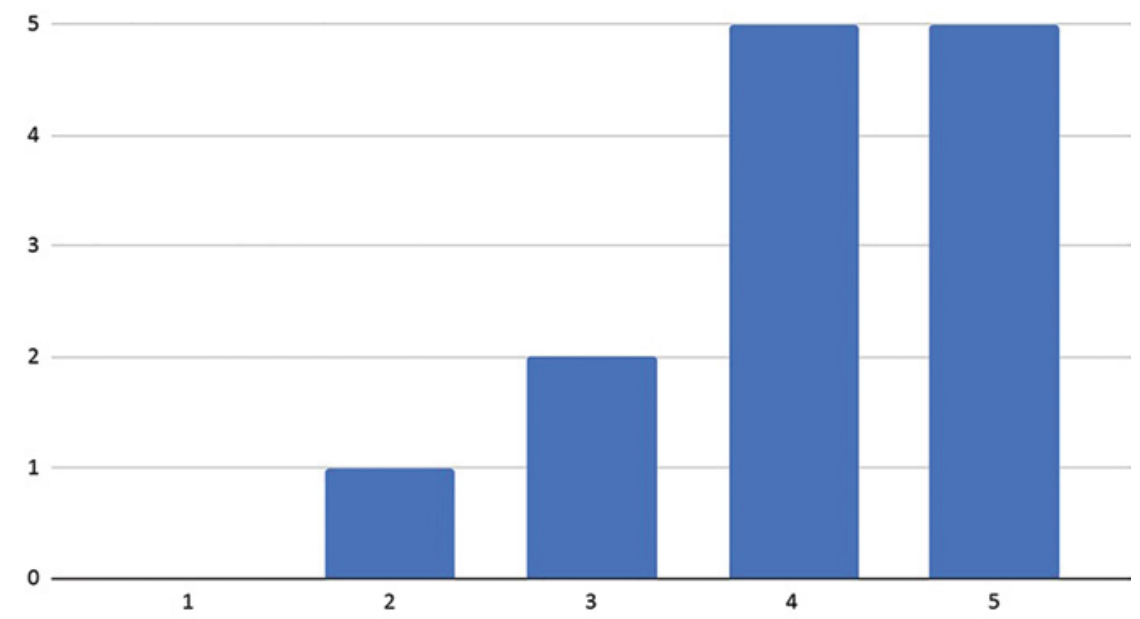

The web conferencing sessions have supported my mental wellbeing during isolation

5

4

3

2

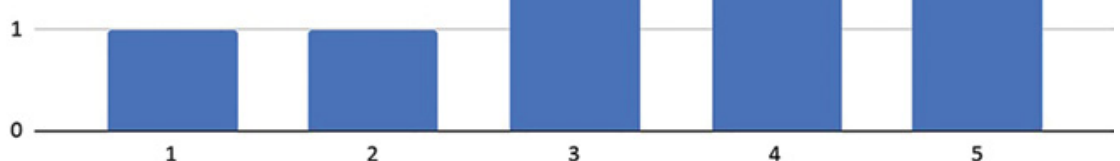

1

2

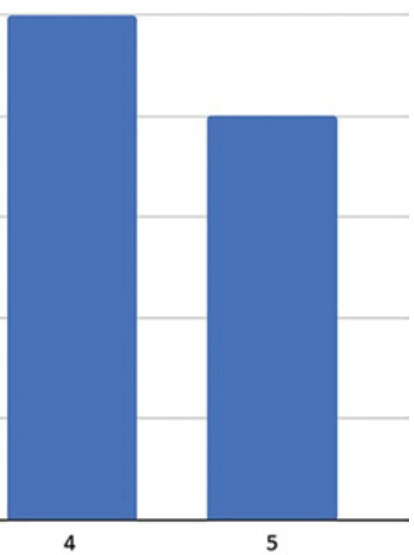

FIGURES $2 \mathrm{~A}-\mathrm{B}$ Students were asked to rate how highly they agreed with the heading statements. The horizontal axis indicates the quantity of students and the vertical axis the agreement of the statement, with 1 being the least and 5 the most.

reflect a poisonous lack of dialogic engagement. Rather, lurking may be a cure for online empowerment (boyd \& Hargittai, 2010). Web-conferencing further facilitates the lurker through the whiteboard feature's anonymous text entries (see Figure 3). As one student explained, it "allowed the freedom of ideas with the sense of anonymity. This encouraged the free flow of respectful comments." 

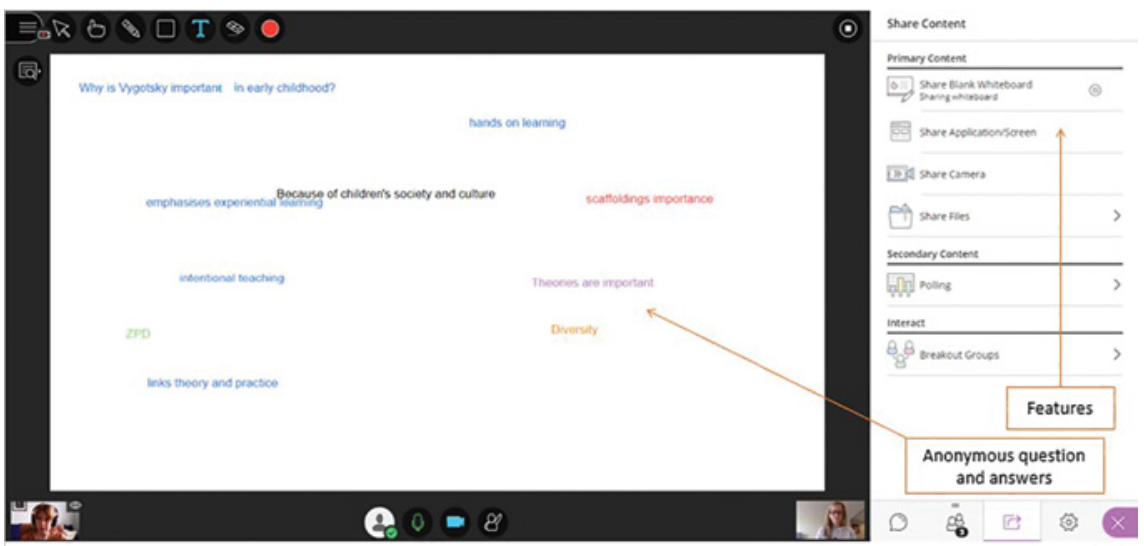

FIGURE 3 The Whiteboard Feature

Whilst web-conferencing may appear visually and dialogically cavernous to the lecturer, student engagement is likely still occurring, visible or otherwise. We, therefore, draw attention to the importance of teaching's visuality whilst simultaneously highlighting the significance of students' unobservable dialogic engagement, that should not be discounted.

Implications for improving students' experiences from this pravda and istina suggest lecturers should accommodate and facilitate the digital dialogues that web-conferencing affords and influences. In the case of student lurkers, although the lecturer may not feel a connection with those in the virtual classroom, students who can see and hear the lecturer may feel connected. Another lurking aspect are recordings; although this might not enable lecturers to see students' presences, it is another visual affordance of online lecturing. As one student positively described, "I can replay the record[ing] later and get a better understanding". We suggest that all forms of student dialogue and visual representation within digital classroom should be embraced, including student lurkers, recordings and the whiteboard feature. Although these may limit the visuality lecturers receive, these digital tools appear to cater to students' online academic and connectivity needs.

\subsection{Lecturers' Received Knowledge: A Meta-istina}

Alongside students' received knowledge (istina) of web-conferencing, as casual lecturers we also received information (istina) from coordinators. Casual lecturers such as ourselves do not design the course content we deliver to students. Although casualised lecturers' curation of this content is not uncommon 
within Australian universities, the topics, images and video clips are developed by coordinators, frequently excluding casual lecturers' pravda (experiences). With the increasing casualisation of lecturers (Hellsten \& Prescott, 2004), this often means students are receiving visually performed web-conferencing sessions that their lecturers are also receiving from coordinators, creating a metaistina. Bergers (1972) described how the image's unique singular placement is consolidated within its meaning. Through the meta-istina, web-conferencing forces the visual to travel between coordinator, lecturer and student. Thus, whilst technologies such as Moocs (Massive Open Online Courses) claim to be standard delivery systems, we contend that the visual is never sterile in its passage toward meaning. Bergers (1972) says this process of reproduction is not necessarily negative but it is "arranged" (33:33) and should be considered as such. In this way, visuality speaks many languages in web-conferencing classrooms, a process that Crary (1992) describes as a "relentless abstraction" (p. 1).

Reflecting on Crary (1992) encourages coordinators and casual lecturers to consider the abstraction of received design within the web-conferencing classroom. Meta-istina embodies representational visual practices within web-conferencing, resulting in a camera obscura to take place. Crary (1992) explains how "whether one excludes or foregrounds certain events and processes at the expense of others affects the intelligibility of the contemporary functioning of power in which we ourselves are enmeshed" (p. 7). Thus, as casual lecturers, by adding personal stories, re-ordering coordinator designs or simply taking pause at specific moments, we contend that we are affecting students' comprehension of ideas. Any notions of students receiving a single visual truth across a program must thus be distilled. It is likely students are receiving in each casual lecturer's web-conferencing performance, a new valuation of visual experience which is abstracted from coordinators design. Our pravda experiences of web-conferencing, curated from coordinators design (istina) and also received from this article's students' surveys (istina), are, therefore, likely to each be obscured to some extent within web-conferencing's visuality. In this way, online lecturing is likely a never-ending process of abstraction in received and experienced meaning.

\subsection{Dialoguing Didactics in the Visual Space}

Returning to the students' istina (survey data) revealed seemingly oppositional preferences for didactic visuality and dialogic connectivity. Whilst forms of dialogism, such as breakout rooms, were polarising (see Figure 4a-b), didactics' predictable visuality was favoured (Figure 4c), challenging Constructivism's supremacy. Within our program that decentred PowerPoints to encourage a collaborative, playful approach, these findings were surprising. 
How helpful have you found the main group/whole class discussion feature?

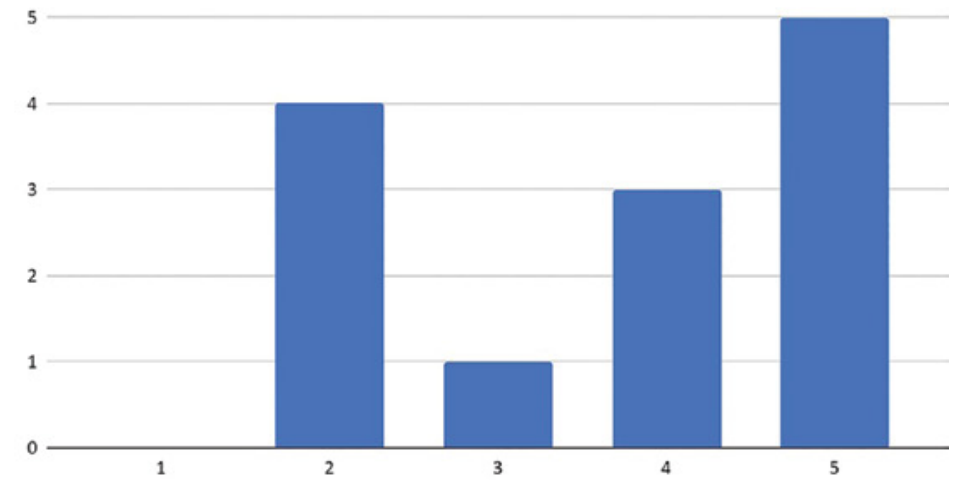

How helpful have you found the Break-Out-Groups feature?

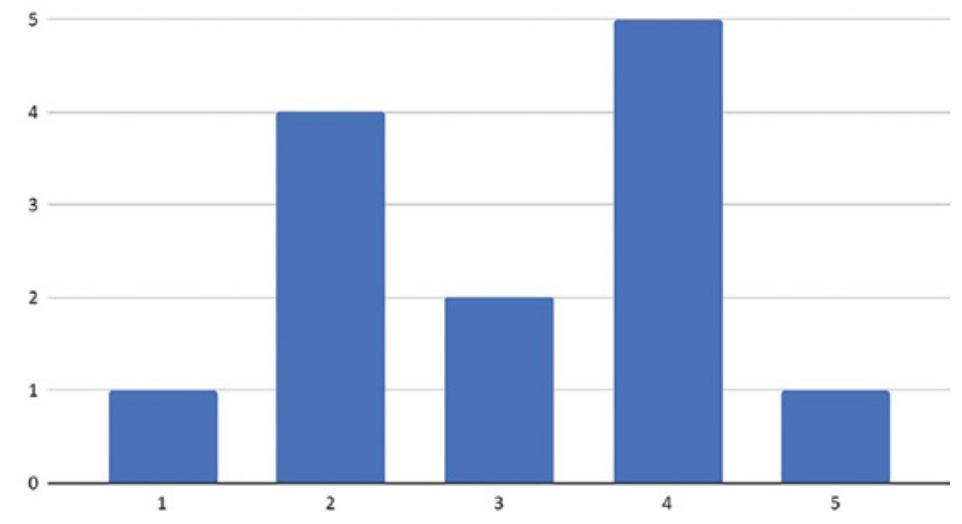

How helpful have you found the main group lecturing style by lecturer feature?

8

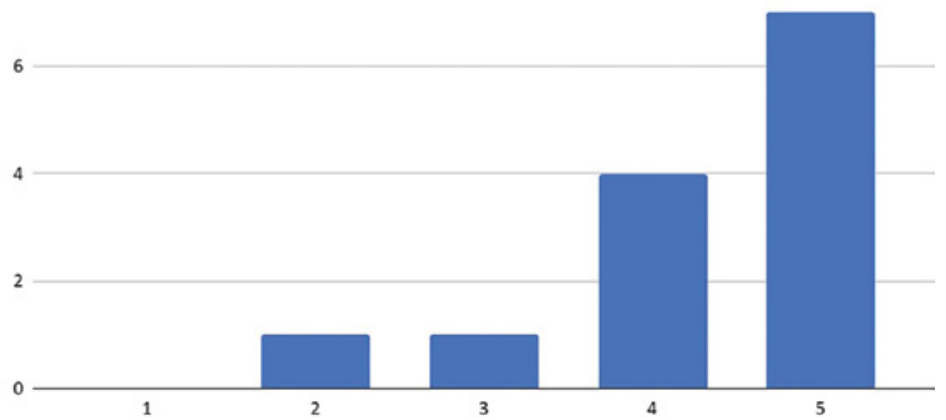

FIGURE 4A-C These graphs reflect students' rating of the headings with the horizontal axis reflecting the quantity of students and the vertical axis their preferences, with 1 being the lowest and 5 the highest. 
Interactive dialogism favours students maintaining a certain level of "selfimposed, academic discipline" (Bawa, 2016, p. 4) which may reflect students' istina as a dependency barrier of Constructivism. Although barriers may exist, dialogic relationships were simultaneously valued by students:

Response 4: "It was really good to be in the same space as my classmates and throw ideas and comments around ... encouraging group discussions, [our lecturer] taking our ideas into consideration."

Response 5: "Our [web-conferencing] sessions would not have been so successful or helpful if it weren't for our tutor, $\mathrm{X}$, who worked really hard to make us feel engaged ... I think the tutor/lecturer holding these sessions are so crucial to online classes."

Engaging with these responses (istina) forced us to acknowledge didactic styles as valuable forms of web-conferencing's visually facilitated dialogue. We contend that offering didactic experiences delivers elements of predictability and consistency, which may support students' needs in the midst of uncertainty and isolation during a pandemic. Similarly, we assert that the visuality of the teaching presence and facilitation of dialogue, whether didactic or dialogic, may influence online students' sense of community and perhaps overcome the learner's social isolation.

Based on these dual student preferences, we suggest lecturers reflect on the visual location of web-conferencing. Students may desire dialogic connectivity but the visuality of the online classroom may not always afford this form of engagement. By facilitating both didactic and dialogic sessions, students' performance anxieties may be reduced, whilst their dialogic responses could be encouraged. We suggest lecturers do not dwell in the silences if dialogic prompts go unanswered; such unresponsiveness may be born out of the limited visuality of the online classroom. Instead, we suggest lecturers adapt their course design in the moment as a response to student engagement, thus continuing the aforementioned process of meta-istina abstraction. We contend that this adaption is necessary if students' needs are to be addressed and supported within web-conferencing.

Reflecting on our programme's dialogic over didactic emphasises, we lastly draw attention to the importance of dialogism and the opportunities that arise for connectivity. Dialogic teaching supports a here-and-now responsiveness toward students' needs, with our experiences (pravda) being of the transaction of self-disclosure. Often used with clients in the therapeutic environment, this approach can deconstruct the linear exchange between lecturer and student 
in the online learning environment and generate opportunity for authentic dialogue. If we consider this positioning of immediate and responsive teaching approaches through a therapeutic lens, the lecturer provides the conditions which are conducive to characteristics of a growth-promoting environment for students. These include the sharing of empathy and empathetic responses, which is considered central to the role of the therapeutic process in Humanistic Psychology (Rogers, 1951). Other examples of therapeutic forms of collaboration include open dialogue and congruence, which can be shared as laughter between lecturers and students. These emphasise relationships and connection, which afford greater capacity for self-motivation, freedom to communicate and increased confidence (Sollarova \& Sollar, 2013).

Integrating therapeutic tools into the online space may build lecturers' capacity to support students' anxieties and trauma experienced from the pandemic. This occurs through relationship forming that prioritises empathy, laughter, and open discussions that are not guarded by traditional distinctions between lecturer and student. In conjunction with this, it is possible that when students are offered a virtual invitation of visually imbued dialogic engagement, there is mutual validation of these spaces affording connection and lecturer presence, potentially reducing anxieties around collaboration.

Through this article's pravda (experienced truth) and istina (received truth), we emphasise the importance of embracing all forms of visually and technologically mediated dialogues as engagement during the pandemic. Although limited visualities, such as student lurking and recordings, may cause lecturers anxiety, we contend that web-conferencing's numerous visual and dialogic features support diverse forms of student connectivity. Lecturers and coordinators may need to reimagine engagement within web-conferencing classrooms to accommodate the affordances and influences of digital technologies and visually diverse dialogues. Students observing lecturers whilst being hidden from view should be embraced as a valid form of engagement. Similarly, lecturers should accentuate empathetic and nurturing dialogues within web-conferencing that encourages the growth of relationships within this environment. Encouraging student-lecturer connectedness within the online's visuality mediated environment requires an open and congruent dialogue that emphasises mutual understanding and acceptance. Although the findings presented in this article are tied to a specific set of students during the pandemic, this pravda and istina may also be applicable to web-conferencing beyond these 
unprecedented circumstances. For instance, the connectivity needs of students and lack of cameras and audio are not isolated to CoviD-19 (Chen et al., 2020). Our implications may, therefore, reflect some of the modern realities for online student engagement and the need for lecturers to adapt to these digital affordances.

Furthermore, we draw attention to the meta-istina occurring within visually diverse web-conferencing classrooms. The casualisation of lecturers reduces the pravda of those teaching and, as with camera obscura, is likely to result in a "relentless abstraction" of delivered content. Although this may not necessarily be negative for students' needs and learning journeys, it distils notions of a unified program. Transporting content from coordinators to casual lecturers and students is thus likely to visually and dialogically obscure the webconference, both performed and received.

We end this article by seeking a greater understanding and emphasis of online students' therapeutic and dialogic needs during social isolation. We contend that lecturers' virtual invitations of visual engagement pose opportunities for more responsive and relational engagement. Consequently, therapeutic teaching within web-conferencing may position the lecturer and students as co-participants with potential and possibility for enhancing student wellbeing. As such, consideration must be given to how web-conferencing can aid visual and dialogic connection through inter-woven therapeutic forms of studentlecturer collaboration.

\section{References}

Akarasriworn, C., \& Ku, H.-Y. (2013). Graduate students' knowledge construction and attitudes toward online synchronous videoconferencing collabozrative learning environments. Quarterly Review of Distance Education, 14(1), 35-48. https:// search.proquest.com/docview/1373183109?accountid $=13552 \&$ rfr_id $=$ info $\% 3$ Axri\%2Fsid\%3Aprimo.

Australian Trade and Investment Commission. (2020). Education data. Australian Government; Australian Trade and Investment Commission. https:/ /www.austrade.gov .au/Australian/Education/Education-data/Current-data/summaries-and-news.

Awbrey, S. M. (2002). Making The Invisible Hand' Visible: The Case for Dialogue About Academic Capitalism. https://our.oakland.edu/handle/10323/7589.

Bakhtin, M. (1986). Speech genres and other late essays (1st ed). University of Texas Press.

Bakhtin, M. (1993). Toward a philosophy of the act (M. Holquist \& V. Liapunov, Eds.; ist ed). University of Texas Press. 
Bawa, P. (2016). Retention in Online Courses: Exploring Issues and Solutions-A Literature Review. SAGE Open, 6(1), https://www.doi.org/10.1177/2158244015621777.

Bergers, J. (1972). Ways of seeing: part 1, reproductions [Video]. https://apo1-a.alma.exli brisgroup.com/discovery/delivery/61RMIT_INST:RMITU/12151271300001341.

Blackall, L. (2020). Technopoly. In Wikipedia. https://en.wikipedia.org/w/index.php? title $=$ Technopoly\&coldid $=978001352$.

Bowers, C. A. (2000). Let them eat data: How computers affect education, cultural diversity, and the prospects of ecological sustainability. University of Georgia Press.

boyd, D, \& Hargittai, E. (2010). Facebook privacy settings: Who cares? First Monday, $15(8), 1-23$.

Crary, J. (1992). Techniques of the Observer: On Vision and Modernity in the Nineteenth Century. MIT Press.

Chatterton, P. (2010). Designing for participant engagement with Elluminate Live. https://www.jisc.ac.uk/elluminateguidance.

Chen, J. C., Dobinson, T., \& Kent, S. (2020). Students' Perspectives on the Impact of Blackboard Collaborate on Open University Australia (oUA) Online Learning. Journal of Educators Online, $17(1)$. https://eric.ed.gov/?id=EJ1241569.

Chen, R. T.-H., Bennett, S., \& Maton, K. (2008). The adaptation of Chinese international students to online flexible learning: Two case studies. Distance Education, 29(3), 307-323. https://www.doi.org/10.1080/01587910802395821.

Cornelius, S. (2014). Facilitating in a demanding environment: Experiences of teaching in virtual classrooms using web conferencing. British Journal of Educational Technology, 45(2), 260-271. https://www.doi.org/10.1111/bjet.12016.

Erichsen, E. A., \& Bolliger, D. U. (2011). Towards understanding international graduate student isolation in traditional and online environments. Educational Technology Research and Development, 59(3), 309-326. https://www.doi.org/10.1007/ s11423-010-9161-6.

Grant, M., \& Cheon, J. (2007). The Value of Using Synchronous Conferencing for Instruction and Students. Journal of Interactive Online Learning, 6(3), 211-226.

Gurevitch, Z. (2000). Plurality in Dialogue: A Comment on Bakhtin. Sociology, 34(2), 243-263. JSTOR. https://www.jstor.org/stable/42858034.

Hannon, J., \& D'Netto, B. (2007). Cultural diversity online: Student engagement with learning technologies. International Journal of Educational Management, 21(5), 418432. https://www.doi.org/10.1108/09513540710760192.

Hellsten, M., \& Prescott, A. (2004). Learning at university: The international student experience. International Education Journal, 5(3), 344-351. https://eric.ed.gov/ ?id=EJ903859.

Hughes, H. (2013). International students using online information resources to learn: Complex experience and learning needs. Journal of Further and Higher Education, 37(1), 126-146. https://www.doi.org/10.1080/0309877X.2011.644778. 
Jandrić, P., Hayes, D., Truelove, I., Levinson, P., Mayo, P., Ryberg, T., Monzó, L. D., Allen, Q., Stewart, P. A., Carr, P. R., Jackson, L., Bridges, S., Escaño, C., Grauslund, D., Mañero, J., Lukoko, H. O., Bryant, P., Fuentes-Martinez, A., Gibbons, A., ... Hayes, S. (2020). Teaching in the Age of Covid-19. Postdigital Science and Education, 1-162. https://www.doi.org/10.1007/s42438-020-00169-6.

Jandrić, P., Ryberg, T., Knox, J., Lacković, N., Hayes, S., Suoranta, J., Smith, M., Steketee, A., Peters, M., McLaren, P., Ford, D. R., Asher, G., McGregor, C., Stewart, G., Williamson, B., \& Gibbons, A. (2019). Postdigital Dialogue. Postdigital Science and Education, 1(1), 163-189. https://www.doi.org/10.1007/s42438-018-0011-x.

Jay, M. (1993). Downcast Eyes: The Denigration of Vision in Twentieth-Century French Thought. University of California Press.

Mardiana, H. (2020). Lecturers' Attitudes towards Online Teaching in the Learning Process. Register Journal, 13(1), 77-98. https://www.doi.org/10.18326/rgt.v13i1.77-98.

Postman, N. (1992). Technopoly: The surrender of culture to technology. Vintage Books.

Pragholapati, A. (2020). covID-19 impact on students [Preprint]. EdArXiv. https://www .doi.org/10.35542/osf.io/895ed.

Rapanta, C., Botturi, L., Goodyear, P., Guàrdia, L., \& Koole, M. (2020). Online University Teaching During and After the Covid-19 Crisis: Refocusing Teacher Presence and Learning Activity. Postdigital Science and Education, 1-23. https://www.doi .org/10.1007/s42438-020-00155-y.

Reushle, S., \& Loch, B. (n.d.). Conducting a trial of web conferencing software: Why, how, and perceptions from the coalface. Turkish Online Journal of Distance Education, $9(3), 19-28$.

Rogers, C. R. (1951). Client-Centred Therapy. Constable.

Sollárová E., Sollár T. (2013) Person-Centred Approach: Theory and Practice in a Nontherapeutic Context. In: Cornelius-White J., Motschnig-Pitrik R., Lux M. (eds) Interdisciplinary Applications of the Person-Centered Approach. Springer, https:// doi-org.ezproxy.lib.rmit.edu.au/10.1007/978-1-4614-7144-8_16.

Stark, S., \& Warne, T. (1999). 'Connecting' the Distance: Relational issues for participants in a distance learning programme. Journal of Further and Higher Education, 23(3), 391-402. https://www.doi.org/10.1080/0309877990230309.

Stiegler, B. (1998). Technics and time: Vol. 1. : the fault of epimetheus. University Press.

White, E. J. (2016). Introducing dialogic pedagogy: Provocations for the early years. Routledge Abingdon.

Zhao, N., \& McDougall, D. (2008). Cultural Influences on Chinese Students' Asynchronous Online Learning in a Canadian University. International Journal of E-Learning \& Distance Education / Revue Internationale Du e-Learning et La Formation à Distance, 22 (2), Article 2. https://www.ijede.ca/index.php/jde/article/view/37.

Yamagata-Lynch, L. C. (2014). Blending online asynchronous and synchronous learning. The International Review of Research in Open and Distributed Learning, 15(2). https://www.doi.org/10.19173/irrodl.v15i2.1778. 